OPEN ACCESS

Edited by:

Philippe Isope

Centre National de la Recherche Scientifique (CNRS), France

Reviewed by:

Marta Perez-Rando,

Massachusetts General Hospital,

Harvard Medical School,

United States

Maxime Assous,

Rutgers University, United States

*Correspondence:

Hiroki Yoshino

psyosino@naramed-u.ac.jp

tThese authors have contributed equally to this work and share first

authorship

Specialty section:

This article was submitted to Cellular Neurophysiology, a section of the journal Frontiers in Cellular

Neuroscience

Received: 10 February 2020 Accepted: 07 April 2020

Published: 12 May 2020

Citation:

Yamamuro $K$, Yoshino $H$, Ogawa $Y$,

Okamura K, Nishihata $Y$,

Makinodan M, Saito $Y$ and Kishimoto T (2020) Juvenile Social Isolation Enhances the Activity of Inhibitory Neuronal Circuits in the

Medial Prefrontal Cortex.

Front. Cell. Neurosci. 14:105. doi: 10.3389/fncel.2020.00105

\section{Juvenile Social Isolation Enhances the Activity of Inhibitory Neuronal Circuits in the Medial Prefrontal Cortex}

\author{
Kazuhiko Yamamuro ${ }^{1 \dagger}$, Hiroki Yoshino ${ }^{1 * \dagger}$, Yoichi Ogawa ${ }^{2}$, Kazuya Okamura $^{1}$, \\ Yosuke Nishihata ${ }^{1}$, Manabu Makinodan ${ }^{1}$, Yasuhiko Saito ${ }^{2}$ and Toshifumi Kishimoto ${ }^{1}$ \\ ${ }^{1}$ Department of Psychiatry, Nara Medical University, Kashihara, Japan, ${ }^{2}$ Department of Neurophysiology, Nara Medical \\ University, Kashihara, Japan
}

During brain development, the design of primary neural networks is primarily determined by environmental stimuli after their formation. In particular, the juvenile period is critical, during which neuronal circuits that consist of both excitatory and inhibitory neurons are remodeled by experience. Social isolation during the juvenile period profoundly affects brain development and contributes to the development of psychiatric disorders. We previously reported that 2 weeks of social isolation after weaning reduced excitatory synaptic inputs and intrinsic excitability in a subtype of layer 5 pyramidal cells, which we defined as prominent h-current ( $\mathrm{PH}$ ) cells, in the medial prefrontal cortex (mPFC) in mice. However, it remains unclear how juvenile social isolation affects inhibitory neuronal circuits that consist of pyramidal cells and interneurons. We found that 2 weeks of social isolation after weaning increased inhibitory synaptic inputs exclusively onto $\mathrm{PH}$ cells with a concomitant deterioration of action potential properties. Although social isolation did not alter the inhibitory synaptic release mechanisms or the number of inhibitory functional synapses on $\mathrm{PH}$ cells, we found that it increased the intrinsic excitability of fast-spiking (FS) interneurons with less excitatory synaptic inputs and more h-current. Our findings indicate that juvenile social isolation enhances the activity of inhibitory neuronal circuits in the $\mathrm{mPFC}$.

Keywords: prefrontal cortex, inhibitory circuit, neurodevelopment, social isolation, pyramidal cell, fast-spiking cell

\section{INTRODUCTION}

There are certain distinct critical periods during programmed development. Early-life experiences can activate intrinsic mechanisms during these critical periods to increase neuronal plasticity. For example, complete darkness after birth has been reported to limit visual experiences, which leads to an immature visual cortex and a prolonged onset of the visual cortex's critical period (Daw et al., 1995). Therefore, experience is crucial for brain function refinement and young animals, including humans, adapt to the environments in which they live. Neuronal plasticity becomes limited after brain maturation. Therefore, lack of early-life remodeling and consolidation of circuits might cause dysregulated information processing, which is associated with neurodevelopmental psychiatric disorders, such as schizophrenia and autism spectrum disorder (LeBlanc and Fagiolini, 2011; Takesian and Hensch, 2013; Nelson and Valakh, 2015). 
Juvenile social experiences substantially affect brain function and behavior in humans and other species (Freedman et al., 1961; Chugani et al., 2001; Bick et al., 2017). Several studies have reported that aberrant juvenile social experiences have enduring effects on brain structure and function that persist into adulthood (Weaver et al., 2004; Eluvathingal et al., 2006; Makinodan et al., 2012; Yamamuro et al., 2018). It is important to note that these sequelae are not reversed by subsequent foster care in humans or subsequent environmental enrichment in rodents (Chugani et al., 2001; Eluvathingal et al., 2006; Makinodan et al., 2012; Yamamuro et al., 2018). These findings suggest that the juvenile period is critical for brain development promoted by social experience.

We previously studied the effect of juvenile social isolation on the synaptic and intrinsic excitability of layer (L) 5 pyramidal cells in the medial prefrontal cortex (mPFC) in mice. L5 pyramidal cells in the PFC can be classified into at least two subtype populations. One subtype projects to subcortical regions, has thicker apical dendrites, more primary branches, and displays prominent hyperpolarization-activated cation currents (Ih). Conversely, the other subtype projects to the contralateral cortex, has thinner apical dendrites, and lacks prominent Ih (Dembrow et al., 2010; Gee et al., 2012; Lee et al., 2014). We defined L5 pyramidal cells with prominent Ih as PH cells and those without as non-PH cells. We found that 2 weeks of social isolation after weaning reduced excitatory synaptic inputs and the excitability of PH cells (Yamamuro et al., 2018).

For optimized neuronal circuit function in behavior, a proper balance between excitation and inhibition in the circuit is critical (Yizhar et al., 2011). Neurodevelopmental disorders, such as schizophrenia, have underlying imbalances of excitation and inhibition in the neuronal circuits (Gonzalez-Burgos et al., 2015; Foss-Feig et al., 2017). However, it remains unclear how juvenile social isolation affects inhibitory neuronal circuits, including inhibitory synaptic inputs to L5 pyramidal cells and interneurons as upstream inhibitory synaptic transmission.

It has been reported that $\gamma$-aminobutyric acid (GABA)mediated inhibition influences cortical network activity and maturation (Buzsáki et al., 2013). In the rodent neocortex, inhibitory synaptogenesis primarily occurs postnatally and rapidly reaches adult-like inhibitory synapse density levels prior to adolescence (Micheva and Beaulieu, 1996; De Felipe et al., 1997). Moreover, the time course for functional maturation of GABAergic synapses in rodents is similar to that of inhibitory synaptogenesis; specifically, the inhibitory postsynaptic current (IPSC) frequency only becomes significant after birth with the IPSCs exhibiting adult-like properties prior to adolescence onset (Le Magueresse and Monyer, 2013). Therefore, the juvenile period might be a sensitive period during which social experience affects inhibitory synaptic transmission.

The neocortex contains a diverse GABAergic interneuron population that collectively regulates the activity of principal neurons. Within this population, a subgroup of interneurons with a fast-spiking (FS) phenotype and powerful perisomatictargeting inhibitory synapses on principal neurons is thought to contribute to the generation of oscillatory network activity, which is important for cognitive function (Freund and Katona,
2007; Lewis et al., 2011). FS interneurons frequently express parvalbumin (PV), which is a calcium-binding protein, and display several distinct electrophysiological properties, including low input resistance, short membrane time constants, narrow action potentials, and a high maximum firing frequency in response to depolarizing current pulses (González-Burgos et al., 2005; Doischer et al., 2008). Interestingly, FS PV interneurons preferentially inhibit L5 pyramidal cells with a prominent Ih compared with L5 pyramidal cells without a prominent Ih (Lee et al., 2014). Subgroups of GABAergic interneurons in the hippocampus and neocortex have been reported to express cholecystokinin, somatostatin (SST), and vasointestinal peptide (Freund and Buzsáki, 1996; Markram et al., 2004; Tricoire et al., 2011). These interneurons typically produce broader action potentials at a lower frequency than those produced by FS interneurons. Although there are functional differences between the subtypes of these interneurons, they are collectively classified as non-FS interneurons based on their morphological and electrophysiological parameters (Kawaguchi and Kondo, 2002; Ascoli et al., 2008; Andersson et al., 2012).

To investigate the effect of juvenile social isolation on inhibitory synaptic inputs onto L5 pyramidal cells and excitability of L5 interneurons, which might output inhibitory synaptic transmission to L5 pyramidal cell, we used the whole-cell patch clamp technique to record IPSCs on L5 pyramidal cells ( $\mathrm{PH}$ and non- $\mathrm{PH}$ cells) and the excitabilities of interneurons (FS cells and non-FS cells), and compared them between group-housed (GH) and isolate-housed mice.

\section{MATERIALS AND METHODS \\ Mice and Housing Conditions}

All the study experiments were approved by the animal care and use committee of Nara Medical University and were conducted according to its guidelines. We used male C57/BL6 mice for all experiments, which were maintained on a fixed 12-h light-dark cycle. After weaning on postnatal day (P) 21, we randomly divided every four male littermates as follows: one was isolated and three were group-reared. The isolated mouse was individually housed from P21 to P35 (early isolation; E-IH) or P35 to P49 (late isolation; L-IH). We considered the GH mice as the typically developing mice. During the non-isolated period, we housed each isolated mouse with its three littermates from P63 to P70.

\section{Electrophysiology}

We prepared brain slices, including the medial frontal cortex (prelimbic cortex), from 63- to 70-day-old mice. We deeply anesthetized the mice using isoflurane and decapitated them. We quickly removed the brain and immersed it in an ice-cold sucrose-based solution bubbled with a mixture of $95 \% \mathrm{O}_{2} / 5 \%$ $\mathrm{CO}_{2}$ gas. The solution contained the following (in $\mathrm{mM}$ ): 230 sucrose, $2.5 \mathrm{KCl}, 25 \mathrm{NaHCO}_{3}, 1.25 \mathrm{NaH}_{2} \mathrm{PO}_{4}, 0.5 \mathrm{CaCl}_{2}$, $10 \mathrm{MgSO}_{4}$, and $10 \mathrm{D}$-glucose. We sectioned the frontal cortex into $330 \mu \mathrm{m}$-thick slices in the coronal plane using a vibrating tissue slicer (Vibratome 1000 Plus 102, Pelco International, Redding, CA, USA). We incubated the slices for at least 
$60 \mathrm{~min}$ in a chamber filled with standard artificial cerebrospinal fluid (ACSF; mM) and continuously bubbled it with a gas mixture at $32^{\circ} \mathrm{C}$ containing (in $\mathrm{mM}$ ) the following: $125 \mathrm{NaCl}$, $2.5 \mathrm{KCl}, 25 \mathrm{NaHCO}_{3}, 1.25 \mathrm{NaH}_{2} \mathrm{PO}_{4}, 2.0 \mathrm{CaCl}_{2}, 1.0 \mathrm{MgCl}_{2}$, and $25 \mathrm{D}$-glucose. Next, we maintained the slices in ACSF at $25^{\circ} \mathrm{C}$. Following incubation, we transferred the submerged slices to a recording chamber and superfused them at a flow rate of $2 \mathrm{ml}$ per min with the ACSF saturated with the aforementioned gas mixture at $32^{\circ} \mathrm{C}$.

We visualized the cells using an upright microscope (BW50WI, Olympus, Japan) equipped with infrared illumination and differential interference contrast video microscopy. We voltage- or current-clamped the L5 neurons of prelimbic cortex in the conventional whole-cell configuration using a Multiclamp 700A amplifier (Axon Instruments). We pulled patch pipettes from borosilicate glass and filled them with an intracellular solution containing the following (in $\mathrm{mM}$ ): $141 \mathrm{~K}$-gluconate, $4 \mathrm{KCl}, 2 \mathrm{MgCl}_{2}, 2 \mathrm{Mg}$-ATP, $0.3 \mathrm{Na}-\mathrm{GTP}$, 0.2 EGTA, and 10 HEPES with a $\mathrm{pH}$ of 7.25 achieved using $\mathrm{KOH}$ to record excitatory postsynaptic current (EPSC) from interneurons. To record the IPSC from pyramidal cells, we used an intracellular solution containing the following (in $\mathrm{mM}$ ) $95 \mathrm{~K}$ gluconate, $50 \mathrm{KCl}, 2 \mathrm{MgCl}_{2}, 2 \mathrm{Mg}$-ATP, $0.3 \mathrm{Na}-\mathrm{GTP}, 0.2$ EGTA, and 10 HEPES with $\mathrm{pH} 7.25$ achieved using $\mathrm{KOH}$. All the recorded membrane potentials were corrected for $13 \mathrm{mV}$ liquid junction potential that was measured as previously described (Neher, 1992). We controlled data acquisition and stimulation using Signal 4 software with Power 1401 interface equipment (Cambridge Electronic Design).

\section{Neuron Classification}

We visually identified the pyramidal cells and interneurons prior to the aforementioned recordings. To distinguish FS interneurons from non-FS interneurons, depolarizing current steps were used to analyze the firing response of each interneuron. We determined the single spike properties for spikes elicited by near-threshold current injections, and quantified spike-frequency adaptation as the ratio between the last and first inter-spike interval in spike trains evoked by $500-\mathrm{ms}$ depolarizing steps. Cells were classified FS if they exhibited the following characteristics: (1) narrow spikes (duration at half peak amplitude $\leq 0.6 \mathrm{~ms}$ ); (2) large after hyperpolarizing potentials (amplitude $\geq 15 \mathrm{mV}$ ); and (3) no significant spike-frequency adaptation (adaptation ratio $\leq 1.2$ ). These criteria might have led to the exclusion of some FS neurons but ensured that cells that were included were FS cells (Supplementary Figures S1A,B). As previously reported (Kawaguchi and Kubota, 1997; Galarreta and Hestrin, 2002; Pawelzik et al., 2002), there is a high correlation between FS electrical properties and PV expression.

\section{Voltage Clamp Recordings}

For voltage-clamp recordings, pipette capacitance was compensated while series resistance was continuously monitored and not compensated. We only used recordings with a stable series resistance of $<20 \mathrm{M} \Omega$ in the subsequent analyses. Current signals were low-pass filtered at $600 \mathrm{~Hz}$ and digitized at a sampling frequency of $10 \mathrm{kHz}$. We held the pyramidal cells at $-70 \mathrm{mV}$ to record the postsynaptic current. As previously described, we used high-chloride intracellular solution to record IPSC and normal chloride intracellular solution to record EPSC. We recorded spontaneous inhibitory postsynaptic currents (sIPSCs) in ACSF with $10 \mu \mathrm{M}$ CNQX, an AMPA/kainite receptor antagonist, and recorded spontaneous excitatory postsynaptic currents (sEPSCs) in ACSF lacking GABAergic antagonists to maintain both excitatory and inhibitory neuronal activity in the slice. Moreover, we recorded tetrodotoxin (TTX)resistant miniature IPSCs (mIPSCs) in the presence of $10 \mu \mathrm{M}$ CNQX and $1 \mu \mathrm{M}$ TTX. We also recorded miniature EPSCs (mEPSCs) in the presence of $10 \mu \mathrm{M}$ gabazine and $1 \mu \mathrm{M}$ TTX. To record evoked IPSCs (eIPSCs), cells were electrically stimulated using a pipette fabricated with theta-type capillary glass pulled to an open tip diameter of 3-5 $\mu \mathrm{m}$ and filled with ACSF. The eIPSC was recorded in ACSF containing $10 \mu \mathrm{M}$ CNQX. We connected a silver bipolar electrode inserted into the theta pipette to an A365 stimulus isolation unit (World Precision Instruments) that was commanded using transistor-transistor logic compatible pulses. The stimulation pipette was placed in L5 at 100-200 $\mu \mathrm{m}$ from the soma of the recorded pyramidal cell and in L3 apically from the soma of the recorded pyramidal cell and a constant-current stimulus (50 $\mu$ s in duration) at $0.2 \mathrm{~Hz}$ was delivered.

\section{Current-Clamp Recordings}

For current-clamp recordings, we monitored and canceled series resistance using a bridge circuit; further, pipette capacitance was compensated. Voltage signals were low-pass filtered at $10 \mathrm{kHz}$ and digitized at $20 \mathrm{kHz}$. The baseline membrane potential was maintained at approximately $-70 \mathrm{mV}$ through current injection. To examine action potential and subthreshold membrane properties, we recorded the membrane potential responses to hyperpolarizing and depolarizing current pulses (500 $\mathrm{ms}$ in duration).

We assessed the Ih magnitude by measuring the voltage sag at hyperpolarization induced by a $-50 \mathrm{pA}$ current injection and calculated the sag ratio (sag-R) as previously described (Yamamuro et al., 2018); and defined cells with $>5 \%$ sag- $\mathrm{R}$ as prominent Ih $(\mathrm{PH})$ cells and the other cells as non-PH cells (Yamamuro et al., 2018). There have been recent reports on the definitions of L5 pyramidal cell subtypes using a similar method with the combined current values, including Ih-induced sag (Lee et al., 2014; Yamamuro et al., 2018).

\section{Data Analyses}

We analyzed sIPSCs and mIPSCs using Mini Analysis software (Synaptosoft). For each cell, we detected and analyzed all events for $5 \mathrm{~min}$ (sPSC) or $10 \mathrm{~min}$ (mPSC), and used scatter plots of the intrinsic membrane property data to allow the explicit display of the variations.

We presented the data as mean \pm standard error of the mean through standard bar charts or line plots. Statistical analyses were performed using Prism (Graphpad). We determined statistical differences using student's t-tests, Mann-Whitney test, or two-factor analyses of variance (ANOVAs) followed by Tukey's honest significant difference test. For repeated-measures data, 
multivariate ANOVAs was used when the variance/covariance matrix was not circular or when the assumption of equality between the variance/covariance matrices was rejected. Betweengroup differences in the means were considered significant at $p<0.05$.

\section{RESULTS}

\section{Juvenile Social Isolation Increased Inhibitory Synaptic Inputs Onto PH Cells}

We previously reported that juvenile social isolation decreased excitatory synaptic inputs onto PH cells (Yamamuro et al., 2018). Synaptic connections and intrinsic neuronal excitability are controlled by homeostatic mechanisms that maintain stable neuronal function (Davis, 2013). Therefore, decreases in excitatory synaptic inputs onto $\mathrm{PH}$ cells induced by social isolation might be compensated for by decreased inhibitory synaptic inputs onto $\mathrm{PH}$ cells. Alternatively, since visual deprivation during the critical period enhances GABAergic inhibition in the visual cortex in mice (Nahmani and Turrigiano, 2014; Kannan et al., 2016), the lack of social experience might potentiate GABAergic inhibition in the $\mathrm{mPFC}$. To investigate these possibilities, we recorded the sIPSCs of L5 pyramidal cells in the $\mathrm{mPFC}$ during adulthood and determined the cell-type specific effects of juvenile social isolation from P21 to P35 (E$\mathrm{IH}$ ) on inhibitory synaptic inputs onto $\mathrm{PH}$ cells and non-PH cells (Figure 1A). Isolated mice exhibited a significant increase in the frequency of sIPSCs on PH cells but not on non-PH cells (Figures 1B,C; left). There were no significant differences in the sIPSC amplitudes in either $\mathrm{PH}$ or non-PH cells between $\mathrm{GH}$ mice and E-IH mice (Figures 1B,C; right). Moreover, we analyzed the mIPSCs in L5 pyramidal cells and observed that social isolation had no effect on mIPSC frequency or amplitude in either PH or non-PH cells (Figure 1D). These findings indicated that social isolation enhanced inhibitory synaptic inputs onto $\mathrm{PH}$ cells, which could subsequently lower the excitability of $\mathrm{PH}$ cells. We observed that $\mathrm{PH}$ cells in the E-IH mice fired at a significantly lower spike frequency during a 100-pA current injection (Supplementary Figures S2A,C); further, they had a higher spike threshold (Supplementary Figures S2A,D) than that observed in the $\mathrm{GH}$ mice, which is consistent with previous findings (Yamamuro et al., 2018). Although social isolation did not affect the spike amplitudes (Supplementary Figures S2A,B), sag-R (Supplementary Figure S2E), or input resistance (Supplementary Figure S2F), we found a negative correlation between the sag- $\mathrm{R}$ and input resistance in both the $\mathrm{GH}$ and $\mathrm{E}-\mathrm{IH}$ groups (Supplementary Figure S2G). These results suggest that juvenile social isolation increased inhibitory inputs and lowered the excitability of $\mathrm{PH}$ cells but not non-PH cells.

\section{The Early Juvenile Period Is Critical for Social Isolation to Affect Inhibitory Synaptic Inputs Onto and the Intrinsic Excitability of PH Cells}

We previously reported that late social isolation (P35 to P49) did not affect the excitatory synaptic inputs onto and excitability

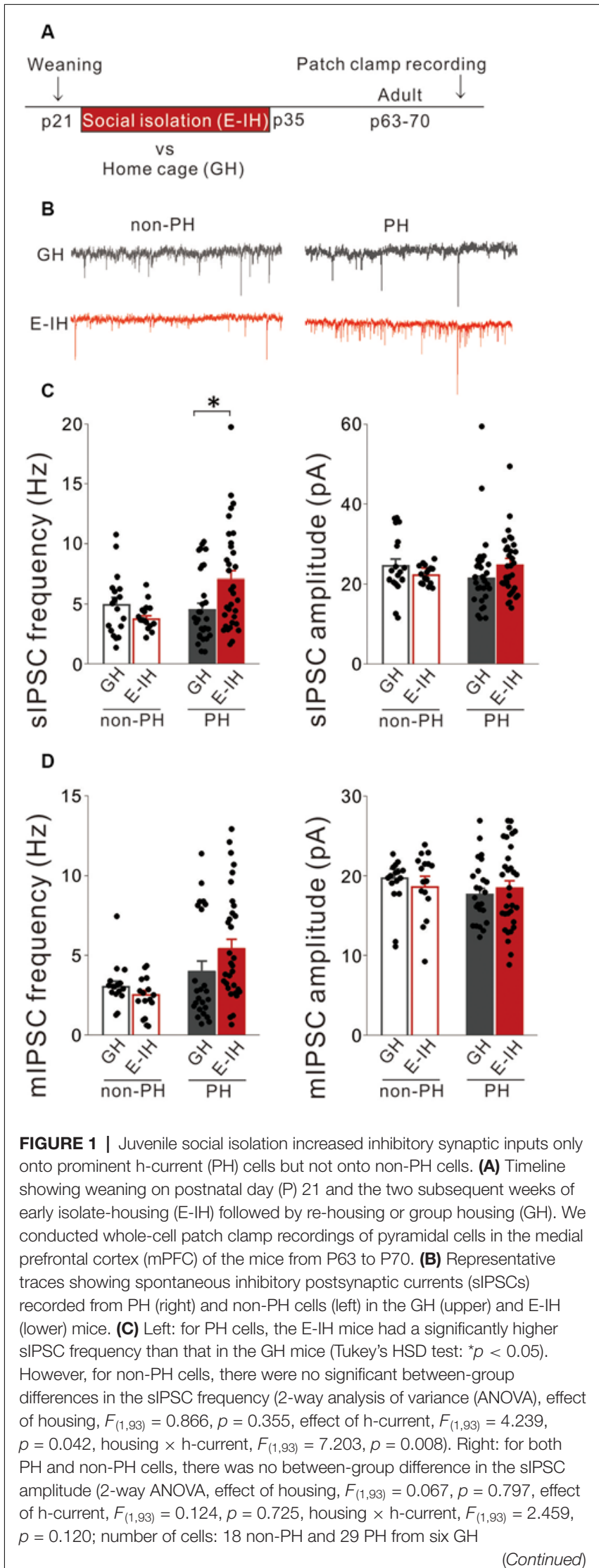


FIGURE 1 | Continued

mice: 16 non-PH and $34 \mathrm{PH}$ from six E-IH mice). (D) Left: there was no significant between-group difference in the miniature IPSC (mIPSC) frequency in either $\mathrm{PH}$ or non-PH cells (2-way ANOVA, effect of housing, $F_{(1,84)}=0.531$, $p=0.468$, effect of h-current, $F_{(1,84)}=9.366,{ }^{* *} p=0.003$,

housing $\times$ h-current, $\left.F_{(1,84)}=2.409, p=0.125\right)$. Right: there was no significant between-group difference in the mIPSC amplitude in $\mathrm{PH}$ or non-PH cells (2-way ANOVA, effect of housing, $F_{(1,84)}=0.024, p=0.878$, effect of h-current, $F_{(1,84)}=1.274, p=0.262$, housing $\times$ h-current, $F_{(1,84)}=0.987$, $p=0.323$; number of cells: 16 non-PH and $16 \mathrm{PH}$ from six GH mice: 24 non- $\mathrm{PH}$ and $32 \mathrm{PH}$ from six $\mathrm{E}-\mathrm{HH}$ mice).

of PH cells (Yamamuro et al., 2018). Similarly, we hypothesized that late social isolation did not affect inhibitory synaptic inputs onto $\mathrm{PH}$ cells. Therefore, we investigated whether late social isolation (L-IH; P35 to P49) affected the inhibitory synaptic inputs and action potential properties in L5 pyramidal cells of the mPFC using the previously used protocol (Yamamuro et al., 2018; Figure 2A). Similarly to our previous report (Yamamuro et al., 2018), we observed no differences in the spike amplitude (Supplementary Figure S3A), spike frequency during a depolarizing current injection (Supplementary Figure S3B), or spike threshold (Supplementary Figure S3C) between the $\mathrm{L}-\mathrm{IH}$ and $\mathrm{GH}$ mice in either $\mathrm{PH}$ or non-PH cells. Although social isolation did not affect the sag- $\mathrm{R}$ or input resistance (Supplementary Figures S3D,E), we observed a negative correlation between the sag- $\mathrm{R}$ and input resistance in both the GH and E-IH mice (Supplementary Figure S3F). Further, we did not observe any significant differences in the frequency or amplitude of sIPSCs in PH cells and non-PH cells between the L-IH and GH mice (Figure 2B) or in the frequency or amplitude of mIPSCs (Figure 2C). These results indicate that P21 to P35 is a sensitive developmental period during which social isolation specifically affects inhibitory synaptic inputs and excitability of pyramidal cells in the mPFC.

\section{Social Isolation Did Not Affect the Number of Functional Inhibitory Synapses or Inhibitory Neurotransmitter Release Mechanisms in Perisomatic and Apical Dendritic Inhibition of PH Cells}

We previously reported that social isolation during the critical juvenile period reduced the sEPSC and mEPSC frequency potentially by reducing functional excitatory synapses on $\mathrm{PH}$ cells only (Yamamuro et al., 2018). However, in the present study, we found that social isolation increased the sIPSC frequency but not the mIPSC frequency. Since social isolation did not affect the mIPSC frequency, it is not plausible that the mechanisms through which social isolation increases the sIPSC frequency in $\mathrm{PH}$ cells involve increased functional inhibitory synapses or inhibitory neurotransmitter release onto $\mathrm{PH}$ cells. Therefore, to verify this assumption, we measured eIPSCs evoked by stimulation electrodes placed in L5 lateral to the soma of the recorded pyramidal cell, which stimulates perisomatic inhibition, and determined the paired-pulse ratio (PPR) and coefficient of variation $(\mathrm{CV})$ of the amplitude. We calculated the inverse squared value of $\mathrm{CV}\left(1 / \mathrm{CV}^{2}\right)$ and used it as a standard measure

\section{A}

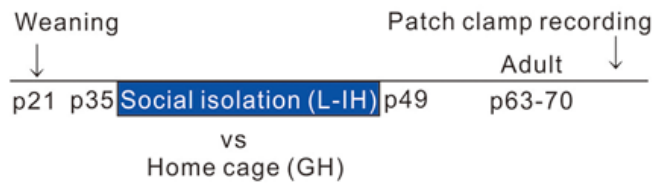

B
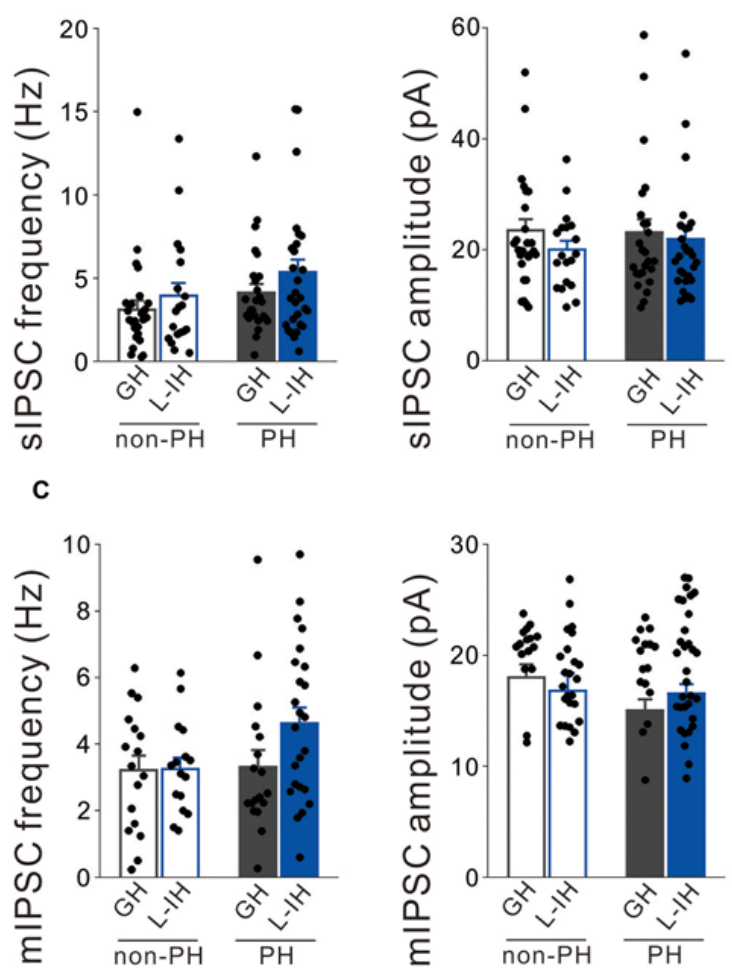

FIGURE 2 | Social isolation did not affect inhibitory synaptic inputs onto L5 pyramidal cells after the critical period. (A) Timeline showing weaning on postnatal day (P) 21 and the 2 weeks of late isolate-housing $(L-H)$ from P35 followed by re-housing or group housing $(\mathrm{GH})$. We conducted whole-cell patch clamp recordings from mPFC pyramidal cells in adulthood. (B) Left: there were no significant between-group differences in the spontaneous inhibitory postsynaptic current (sIPSC) frequency in either prominent $h$-current $(\mathrm{PH})$ or non-PH cells (2-way ANOVA, effect of housing, $F_{(1,94)}=2.494$, $p=0.118$, effect of h-current, $F_{(1,94)}=3.424, p=0.067$, housing $\times$ h-current, $\left.F_{(1,94)}=0.099, p=0.754\right)$. Right: there was no between-group difference in sIPSC amplitude in either $\mathrm{PH}$ or non-PH cells (2-way ANOVA, effect of housing, $F_{(1,94)}=1.3, p=0.257$, effect of h-current, $F_{(1,94)}=0.135$, $p=0.714$, housing $\times$ h-current, $F_{(1,94)}=0.304, p=0.583$; number of cells: 26 non-PH and $25 \mathrm{PH}$ from six GH mice: 19 non-PH and $28 \mathrm{PH}$ from six $\mathrm{L}-\mathrm{IH}$ mice). (C) Left: there were no significant between-group differences in the miniature IPSC (mIPSC) frequency in either $\mathrm{PH}$ or non- $\mathrm{PH}$ cells (2-way ANOVA, effect of housing, $F_{(1,75)}=2.035, p=0.158$, effect of h-current, $F_{(1,75)}=2.437, p=0.123$, housing $\times$ h-current, $\left.F_{(1,75)}=1.851, p=0.178\right)$. Right: there was no between-group difference in the mIPSC amplitude in either $\mathrm{PH}$ or non-PH cells (2-way ANOVA, effect of housing, $F_{(1,75)}=0.108$, $p=0.744$, effect of h-current, $F_{(1,75)}=3.429, p=0.068$, housing $\times$ h-current, $F_{(1,75)}=2.725, p=0.103$; number of cells: 17 non-PH and $22 \mathrm{PH}$ from six GH mice: 16 non-PH and $24 \mathrm{PH}$ from six $\mathrm{L}-\mathrm{IH}$ mice).

for evaluating inhibitory synaptic function (Kullmann, 1994). PPR alterations indicate changes in neurotransmitter release mechanisms at presynaptic terminals (Zucker and Regehr, 2002) 
while $1 / \mathrm{CV}^{2}$ alterations suggest changes in either the probability of transmitter release, number of functional synapses, or both (Kullmann, 1994). We found no significant differences in the PPR in either PH or non-PH cells between the GH and E-IH mice (Figure 3A), which indicated that juvenile social isolation did not affect the mechanisms of presynaptic transmitter release. Moreover, there were no significant differences in the $1 / \mathrm{CV}^{2}$ in either $\mathrm{PH}$ or non- $\mathrm{PH}$ cells between the $\mathrm{GH}$ and E-IH mice (Figure 3B). To further investigate whether social isolation affected the number of functional inhibitory synapses, we analyzed the intensity-amplitude curves recorded from IPSCs evoked by electrical stimulation using current that was incrementally increased at $0.5-\mu \mathrm{A}$ steps from the threshold intensity. We observed no significant differences in the eIPSC in either PH or non-PH cells between the GH and E-IH mice (Figure 3C). These results indicate that juvenile social isolation does not increase the number of functional inhibitory synapses or alter the presynaptic transmitter release mechanisms in perisomatic inhibition of $\mathrm{PH}$ cells. However, it is also possible that increased sIPSC frequency resulting from social isolation could involve an increased number of inhibitory synapses or altered neurotransmitter release mechanisms in inhibitory synaptic inputs in the distal site of the apical dendrites in PH cells. Therefore, we placed a stimulation electrode in L3, which includes the apical dendrites, of an L5 pyramidal cell and measured eIPSC by stimulating apical dendritic inhibition. We did not observe differences in the PPR (Figure 3D), 1/CV (Figure 3E), or intensity-amplitude curves recorded from the eIPSCs (Figure 3F). These findings further support the conclusion that social isolation neither affects the number of functional inhibitory synapses nor the presynaptic inhibitory neurotransmitter release mechanism at the perisomatic and apical dendritic site in both $\mathrm{PH}$ and non-PH cells.

\section{Social Isolation During the Juvenile Period Altered Excitability and Excitatory Synaptic Inputs of FS Interneurons}

Given that there was no change in the inhibitory synapses and presynaptic inhibitory neurotransmitter release mechanism in $\mathrm{PH}$ cells, it is possible that increased sIPSC frequency in $\mathrm{PH}$ cells induced by social isolation might involve increased excitability of interneurons with inhibitory inputs onto $\mathrm{PH}$ cells. The neocortex hosts a diverse GABAergic interneuron population that collectively regulates the activity of principal neurons. Within this population, an interneuron subgroup population with an FS phenotype has powerful perisomatic-targeting inhibitory synapses on pyramidal cells, which frequently express the calcium-binding protein $\mathrm{PV}$ and present several distinct electrophysiological properties, including low input resistance, short membrane time constants, narrow action potentials, and a high maximum firing frequency in response to depolarizing current pulses (González-Burgos et al., 2005; Doischer et al., 2008). Therefore, we examined whether social isolation altered action potential properties in L5 FS interneurons in the mPFC. Prior to recording, we identified FS interneurons based on their action potential ("Materials and Methods" section Supplementary Figures S1, S4A). There were no significant between-group differences in the spike amplitude (Figure 4B) or frequency (Figure 4C). Notably, FS interneurons in the E-IH mice fired at a significantly lower spike threshold than those in the GH mice (Figure 4D). Previous studies have reported that PV+ cells (putative FS cells) expressed HCN4 (Hughes et al., 2013). Given the role of HCN channels in decreasing cellular excitability, it is possible that social isolation decreases the Ih current (expressed as sag-R) of FS cells, which results in a lowered spike threshold. Therefore, we investigated whether social isolation influenced the sag-R of L5 FS interneurons. We found a significantly larger sag- $\mathrm{R}$ and higher input resistance in FS interneurons in the E-IH mice (Figures $4 \mathrm{E}, \mathrm{F}$ ). Notably, there was a positive correlation between the sag- $\mathrm{R}$ and input resistance in both the GH and E-IH mice (Figure 4G), which was in contrast with the negative correlation observed between the sag-R and input resistance in L5 pyramidal cells (Supplementary Figures S2G, S3F). A larger sag-R indicates more h-current in FS interneurons, which decreases cellular excitability. It is possible that more excitable FS interneurons with lower spike thresholds and higher input resistance in the $\mathrm{E}-\mathrm{IH}$ mice might paradoxically have a larger sag- $\mathrm{R}$ as a compensatory effect. To investigate whether these alterations simultaneously occur in FS interneurons, we evaluated the membrane properties of FS interneurons exposed to juvenile social isolation using 3-dimensional plots of these three values (Supplementary Figure S4A). Compared with the GH mice, we detected an FS cell subgroup in the E-IH mice that simultaneously had a low spike threshold, high input resistance, and large sag- $R$ (Supplementary Figure S4A; right, circle). This suggests that juvenile social isolation increased the intrinsic excitability of FS interneurons, which led to a simultaneously lower spike threshold, increased input resistance, and increased sag- $\mathrm{R}$ in an FS interneuron subgroup in L5 of the mPFC.

FS interneuron activation mediated by excitatory inputs is crucial for pyramidal cell synchronization in the gamma frequency band related to cognitive function (Rotaru et al., 2011). Increased excitability of FS interneurons resulting from juvenile social isolation might be followed by increased excitatory synaptic inputs onto FS interneurons. Contrastingly, it might be followed by compensatory reduction of excitatory synaptic inputs onto FS interneurons. To assess these possibilities, we recorded sEPSCs on FS interneurons in both the GH and $\mathrm{E}-\mathrm{IH}$ mice. We observed a significant decrease in the sEPSC frequency on FS interneurons in the E-IH mice (Figures $\mathbf{4 H}, \mathbf{I}$; left). Contrastingly, there were no significant differences in the sEPSC amplitudes in FS interneurons in the GH and E-IH mice (Figures $\mathbf{4 H}, \mathbf{I}$; right). Further, we analyzed the mEPSCs on FS interneurons and found that juvenile social isolation had no effect on the mEPSC frequency or amplitude in FS cells (Figures 4J,K). These findings suggest that juvenile social isolation decreased excitatory synaptic inputs onto FS cells. Similar to the aforementioned findings (Supplementary Figure S4A), we found that social isolation had a simultaneous effect on the spike threshold, sag-R, and sEPSC frequency in an FS interneuron subgroup (Supplementary Figure S4B; right). 

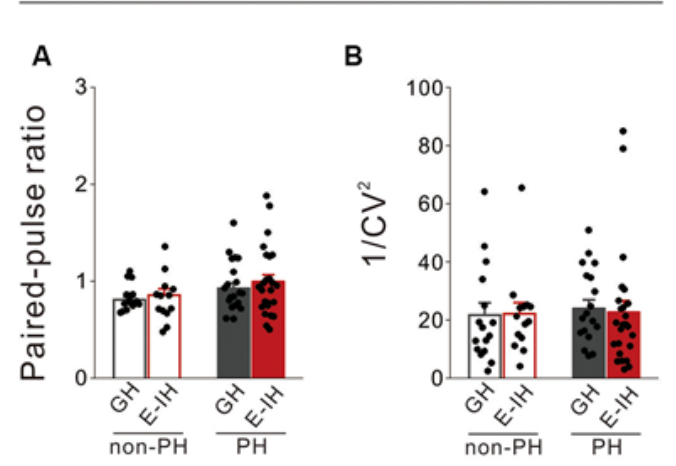

\section{Layer V}

C
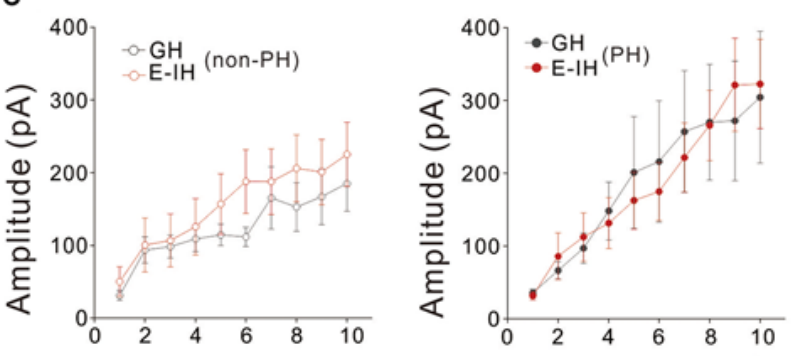

Increment from threshold $(\mu \mathrm{A})$ Increment from threshold $(\mu \mathrm{A})$

\section{Layer III}
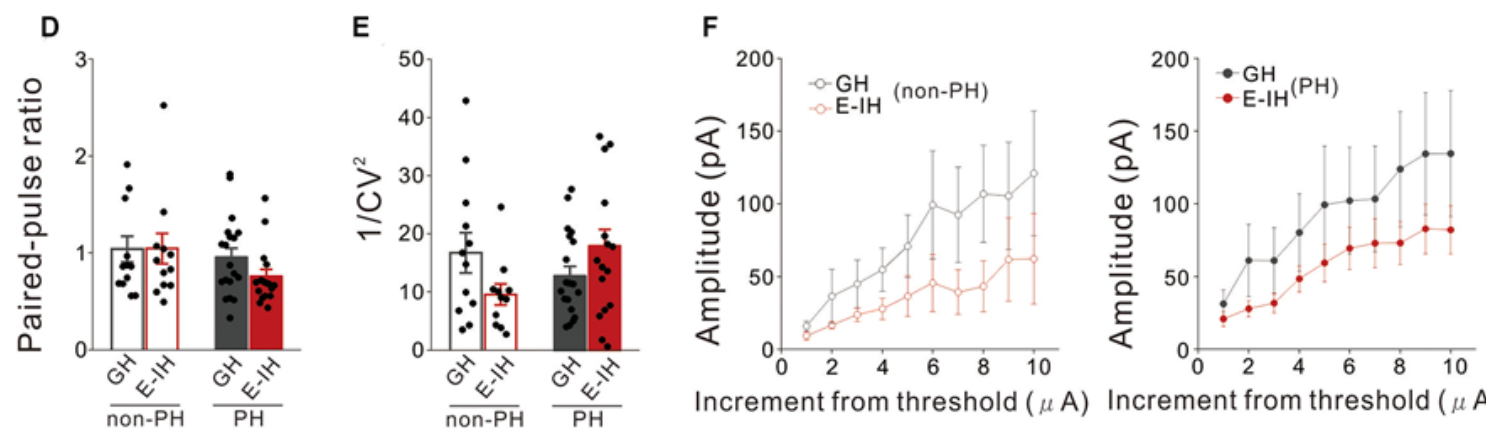

Increment from threshold $(\mu \mathrm{A})$ Increment from threshold $(\mu \mathrm{A})$

FIGURE 3 | Social isolation did not affect the number of functional inhibitory synapses onto or presynaptic inhibitory neurotransmitter release mechanisms in L5 pyramidal cells in the perisomatic and apical dendritic site. (A) There were no significant between-group differences in the paired-pulse ratio (PPR) in prominent h-current $(\mathrm{PH})$ and non-PH cells (2-way ANOVA, effect of housing, $F_{(1,71)}=0.729, p=0.396$, effect of h-current, $F_{(1,71)}=5.458, p=0.022$, housing $\times$ h-current, $F_{(1,71)}=0.107, p=0.745$; number of cells: 17 non- $\mathrm{PH}$ and $20 \mathrm{PH}$ from five GH mice: 13 non-PH and $25 \mathrm{PH}$ from five E-IH mice). (B) There were no significant between-group differences in 1/coefficient of variation (CV) ${ }^{2}$ in $\mathrm{PH}$ or non-PH cells (2-way ANOVA, effect of housing, $F_{(1,69)}=0.0087, p=0.926$, effect of h-current, $F_{(1,69)}=0.186, p=0.668$, housing $\times$ h-current, $F_{(1,69)}=0.148, p=0.702$; number of cells: 16 non-PH and $18 \mathrm{PH}$ from five GH mice: 14 non-PH and $25 \mathrm{PH}$ from five $\mathrm{E}-\mathrm{IH}$ mice). (C) Line plots showing the relationship between the stimulus intensity (increment from the threshold current) and evoked excitatory postsynaptic current (eEPSC) amplitude in non-PH (left) and PH (right) cells. There were no significant between-group differences in eEPSC amplitudes across the stimulation intensities in non-PH (MANOVA, housing $\times$ current step interaction, $F_{(9,250)}=0.176, p=0.996$; left) and PH cells (MANOVA, housing $\times$ current step interaction, $F_{(9,340)}=0.178$, $p=0.996$; right; number of cells: 17 non-PH and $14 \mathrm{PH}$ from five GH mice : 10 non-PH and $22 \mathrm{PH}$ from five E-IH mice). (D) There were no significant between-group differences in the PPR in PH or non-PH cells (2-way ANOVA, effect of housing, $F_{(1,56)}=0.724, p=0.399$, effect of h-current, $F_{(1,56)}=2.804, p=0.100$,

housing $\times$ h-current, $F_{(1,56)}=0.823, p=0.363$; number of cells: 12 non- $\mathrm{PH}$ and $19 \mathrm{PH}$ from five GH mice: 12 non-PH and $17 \mathrm{PH}$ from five $\mathrm{E}-\mathrm{IH}$ mice). (E) There was a significantly higher $1 / \mathrm{CV}^{2}$ in $\mathrm{PH}$ cells than that in non- $\mathrm{PH}$ cells among the early isolation $(\mathrm{E}-\mathrm{IH})$ mice (2-way ANOVA, effect of housing, $F_{(1,54)}=0.160, p=0.691$, effect of h-current, $F_{(1,54)}=0.725, p=0.398$, housing $\times$ h-current, $F_{(1,54)}=5.811, p=0.019$ ) but they did not differ in the group housing (GH) mice (number of cells: 17 non-PH and $14 \mathrm{PH}$ from five GH mice: 10 non-PH and $22 \mathrm{PH}$ from five E-IH mice). (F) Line plots showing the relationship between stimulus intensity and eEPSC amplitude in non- $\mathrm{PH}$ (left) and $\mathrm{PH}$ (right) cells. There were no significant between-group differences in the eEPSC amplitude across stimulation intensities in both non-PH (MANOVA, housing $\times$ current step interaction, $F_{(9,190)}=0.172, p=0.997$; left) and PH cells (MANOVA, housing $\times$ current step interaction, $F_{(9,340)}=0.0055$, $p=0.999$; right; number of cells: 11 non- $\mathrm{PH}$ and $19 \mathrm{PH}$ from five $\mathrm{GH}$ mice: 10 non-PH and $17 \mathrm{PH}$ from five $\mathrm{E}-\mathrm{IH}$ mice).

These findings suggest that social isolation also reduces the sEPSC frequency as a compensatory effect for increased FS interneuron excitability.

\section{Social Isolation During the Juvenile Period Did Not Alter Excitability and Excitatory Synaptic Inputs of Non-FS Interneurons}

Next, to investigate whether juvenile social isolation had similar effects on L5 non-FS interneurons as those on L5 FS interneurons in the $\mathrm{mPFC}$, the action potential properties of L5 non-FS interneurons in both the $\mathrm{GH}$ and $\mathrm{E}-\mathrm{IH}$ mice was determined. There were no differences in the spike amplitude (Figure 5A), spike frequency (Figure 5B), spike threshold (Figure 5C), sag-R (Figure 5D), and input resistance (Figure 5E) between the GH and $\mathrm{E}-\mathrm{IH}$ mice. However, similar to the FS interneurons, we found a positive correlation in the sag- $\mathrm{R}$ and input resistance in both the $\mathrm{GH}$ and E-IH mice (Figure 5F). There were no differences in the sEPSC frequency or amplitude of non-FS interneurons between the $\mathrm{GH}$ and $\mathrm{E}-\mathrm{IH}$ mice (Figure 5G). Further, there were no differences in the mEPSC frequency and amplitude of non-FS interneurons between the GH and E-IH mice (Figure $\mathbf{5 H}$ ). These findings suggest that social isolation does not affect the excitability of and excitatory synaptic inputs onto non-FS interneurons. 
A

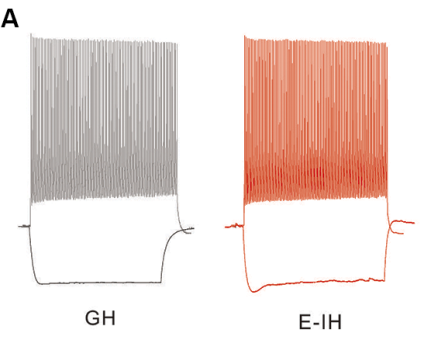

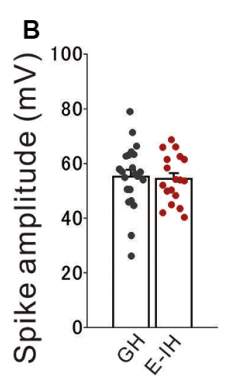

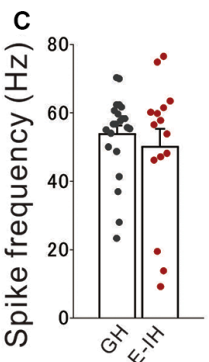

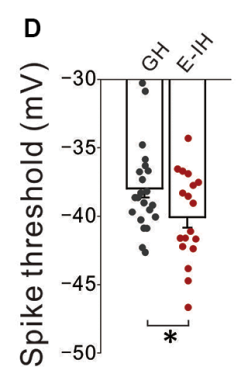
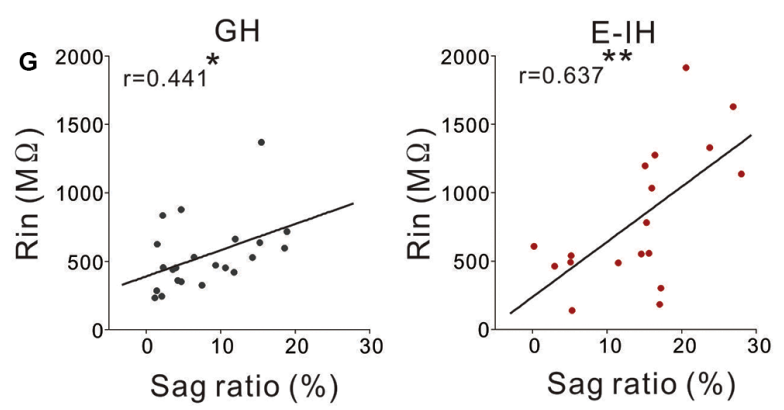

H GH

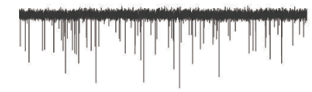

$\mathrm{E}-\mathrm{IH}$

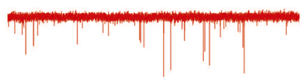

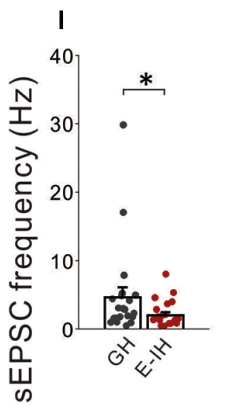

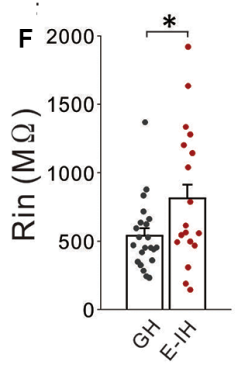

Sag ratio $(\%)$

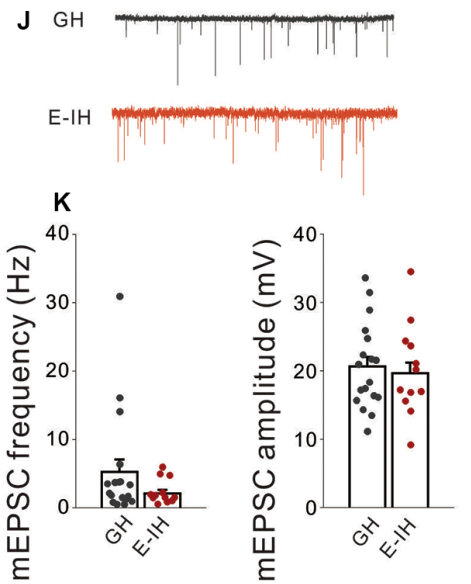

FIGURE 4 | Social isolation increased the intrinsic excitability and decreased excitatory synaptic inputs onto fast-spiking (FS) interneurons. (A) Representative spikes of FS interneurons elicited by a current injection that was $100 \mathrm{pA}$ larger than rheobase recorded in the group-housed (GH; left) and early isolation (E-IH) mice (right). (B) There was no significant between-group difference in the spike amplitude of FS interneurons $\left(t_{(38)}=0.234, p=0.816\right.$; student's $t$-test). (C) There was no significant between-group difference in the spike frequency $\left(t_{(38)}=0.637, p=0.528\right.$; student's $t$-test). (D) The spike threshold in the $\mathrm{E}$ - $\mathrm{HH}$ mice was significantly lower than that in the $\mathrm{GH}$ mice $\left(t_{(38)}=2.050,{ }^{*} p=0.047\right.$; student's $t$-test). (E) The sag ratio in the $\mathrm{E}-\mathrm{IH}$ mice was significantly higher than that in the $\mathrm{GH}$ mice $\left(t_{(38)}=-2.100\right.$, ${ }^{*} p=0.042$; student's $t$-test). (F) The input resistance in the $\mathrm{E}-\mathrm{IH}$ mice was significantly higher than that in the GH mice $\left(t_{(38)}=-2.215,{ }^{*} p=0.033\right.$; student's $t$-test). (G) There was a positive correlation between input resistance and sag ratio in the GH (left) and E-IH mice (right; GH: $r=0.441,{ }^{*} p<0.05 ; \mathrm{E}-\mathrm{IH}: r=0.637$, ${ }^{* *} p<0.01$; Pearson correlation; number of cells in panels (A-G): 22 from $10 \mathrm{GH}$ mice: 18 from nine E-IH mice). (H) Representative traces showing spontaneous excitatory postsynaptic currents (sEPSCs) recorded from FS cells in the GH and E-IH mice. (I) The sEPSC frequency in the E-IH mice was significantly lower than that in the GH mice $\left(U=126,{ }^{*} p=0.046\right.$; Mann-Whitney $U$ test). Moreover, there were no significant between-group differences in the sEPSC amplitude $\left(t_{(37)}=0.010\right.$, $p=0.992$; student's $t$-test; number of cells: 21 from $10 \mathrm{GH}$ mice: 18 from nine E-IH mice). (J) Representative traces showing miniature EPSCs (mEPSCs) recorded from FS cells in the GH and E-IH mice. (K) There were no significant between-group differences in the mEPSC frequency (left) or amplitude (right; $m E P S C$ frequency: $U=83, p=0.305$; Mann-Whitney $U$ test, mEPSC amplitude: $t_{(37)}=0.284, p=0.683$; student's $t$-test; number of cells: 18 from $10 \mathrm{GH}$ mice: 12 from nine E-IH mice).

\section{DISCUSSION}

In this study, we demonstrated that 2 weeks of social isolation increased inhibitory synaptic activity and decreased intrinsic excitability in $\mathrm{PH}$ cells in the $\mathrm{mPFC}$ in the mice. We found that social isolation in the juvenile period between P21 and P35 was critical for the effects to be observed. The increase in the inhibitory synaptic inputs was neither due to alteration of neurotransmitter release mechanisms nor increased functional inhibitory synapses. Social isolation increased the intrinsic 

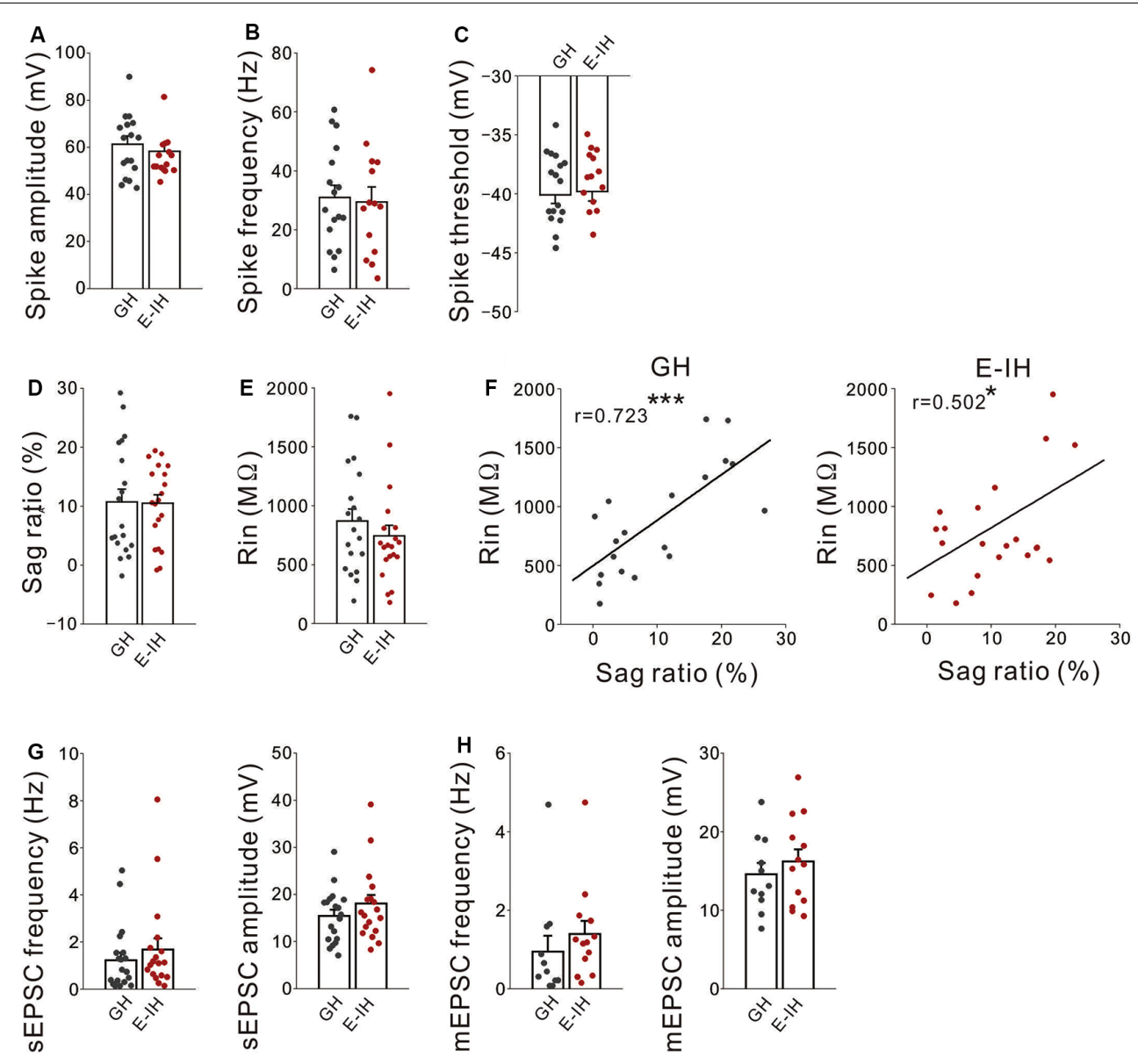

FIGURE 5 | Social isolation did not alter excitatory inputs onto or excitability in non-fast spiking (non-FS) interneuron. (A) There was no significant between-group difference in the spike amplitude in non-FS interneurons $\left(t_{(29)}=1.252, p=0.115\right.$; student's $t$-test). (B) There was no significant between-group difference in the spike frequency ( $t_{(29)}=0.240, p=0.812$; student's $t$-test). (C) There was no significant between-group difference in the spike threshold $\left(t_{(29)}=-0.524, p=0.751\right.$; student's $t$-test; number of cells in panels (A-C): 17 from $10 \mathrm{GH}$ mice: 14 from nine E-IH mice). (D) There was no significant between-group difference in the sag ratio $\left(t_{(37)}=0.055, p=0.957\right.$; student's $t$-test). (E) There was no significant between-group difference in the input resistance $\left(t_{(37)}=0.880, p=0.385 ;\right.$ student's $t$-test). (F) There was a positive correlation between the input resistance and sag ratio in the $\mathrm{GH}$ (left) and early isolation $(\mathrm{E}-\mathrm{HH})$ mice (right; $\mathrm{GH} ; r=0.723^{\star \star \star} p<0.001, \mathrm{E}-\mathrm{IH}$; $r=0.502{ }^{*} p<0.05$; Pearson correlation; number of cells in panels (D-F): 19 from 10 GH mice: 20 from nine E-IH mice). (G) There were no significant between-group differences in the spontaneous excitatory postsynaptic current (SEPSC) frequency (left) or amplitude (right; sEPSC frequency: $U=140$; Mann-Whitney $U$ test, $p=0.358$, sEPSC amplitude: $t_{(35)}=-1.165, p=0.252$; student's $t$-test; number of cells: 19 from $10 \mathrm{GH}$ mice: 18 from nine E-IH mice). (H) There were no significant between-group differences in the miniature EPSC (mEPSC) frequency (left) or amplitude (right; $m E P S C$ frequency: $U=43$; Mann-Whitney $U$ test, $p=0.106$, mEPSC amplitude: $t_{(22)}=-0.762, p=0.454$; student's $t$-test; number of cells: 11 from $10 \mathrm{GH}$ mice: 13 from nine $\mathrm{E}-\mathrm{IH}$ mice).

excitability of FS interneurons with lowered spike threshold and increased input resistance even though there was increased Ih and decreased excitatory synaptic inputs onto FS interneurons. Social isolation did not affect the excitability of non-FS interneurons. These results suggest that social isolation during the critical period enhances the activity of inhibitory neuronal circuits, including PH cells and FS interneurons in the mPFC in mice.

Sensory experience during the developmental period is considered important for the proper construction of neuronal circuits (Holtmaat and Svoboda, 2009). The observed enhanced inhibition of neuronal circuits by social isolation during development is consistent with previous findings regarding sensory deprivation during development (Maffei et al., 2006;
Kannan et al., 2016). Visual deprivation during the critical period has been reported to enhance the amplitude of IPSCs mediated by FS interneurons (Maffei et al., 2006); further, within L4, GABAergic transmission strengthening is mediated by increased postsynaptic GABA receptor density and the density of readily releasable vesicles at interneuron terminals in the visual cortex (Nahmani and Turrigiano, 2014; Petrini et al., 2014). Moreover, GABAergic enhancement is mediated by an increase in both the number of postsynaptic GABAergic synapses and the probability of presynaptic GABA release (Kannan et al., 2016). Although sensory experience and social experience involve different information processing, lack of social experience during the juvenile period might disturb normal neuronal circuit development and induce 
excessive GABAergic inhibition through increased excitability of FS interneurons.

A previous study reported that juvenile social isolation reduced excitatory synaptic inputs onto $\mathrm{PH}$ cells but not onto non-PH cells (Yamamuro et al., 2018). In the present study, we found that juvenile social isolation increased inhibitory inputs onto $\mathrm{PH}$ cells but not non- $\mathrm{PH}$ cells. These findings indicate that juvenile social isolation shifts the excitation/inhibition (E/I) balance toward poor excitation and excessive inhibition in the synaptic inputs onto $\mathrm{PH}$-cells. A tight balance between excitatory and inhibitory synaptic inputs onto neurons is critical for normal brain development and function. Contrastingly, imbalances between excitation and inhibition in synaptic transmission and neural circuits have been implicated in autism spectrum disorders (Cellot and Cherubini, 2014; Nelson and Valakh, 2015). The mPFC shares rich reciprocal connections with the mediodorsal (MD) thalamus (Condé et al., 1990; Ray and Price, 1992, 1993), which has been implicated in learning and memory, cognitive flexibility, and corollary discharge (Parnaudeau et al., 2015; Golden et al., 2016). Previous reports indicate that changes in thalamic volume (Tamura et al., 2010), as well as structural (Tan et al., 2010; Nair et al., 2013) and functional (Nair et al., 2013) connectivity between the PFC and MD thalamus can be observed in autism spectrum disorders. Social isolation induces autism-like behaviors in both humans and animals (Bicks et al., 2015). Several studies have reported that PH cells in the mPFC have axonal projections to subcortical regions including the thalamus (Dembrow et al., 2010; Gee et al., 2012; Lee et al., 2014). Moreover, previous studies have reported changes in the electrophysiological properties and synaptic connectivity of L5 neocortical pyramidal neurons in the autism model (Rinaldi et al., 2008a,b; Qiu et al., 2011; Kalmbach et al., 2015; Brumback et al., 2018; Yamamuro et al., 2018).Therefore, the observed disruption of the E/I balance in $\mathrm{PH}$ cells by social isolation in our study might indicate a potential mechanism for the decreased PFC-MD functional connectivity observed in human autism.

We found that social isolation increased inhibitory synaptic inputs onto PH cells, which was indicated by increased sIPSC frequency; however, it did not affect presynaptic neurotransmitter release mechanisms or the number of functional synapses, which we determined by analyzing the $\mathrm{PPR}$, input-output curve, or $1 / \mathrm{CV}^{2}$ of the eIPSC amplitude on $\mathrm{PH}$ cells. These findings suggest that there could be an increase in the excitability of GABAergic interneurons as the source of inhibitory neurotransmission on $\mathrm{PH}$ cells. It is possible that FS cells are primary candidates for this GABAergic interneuron excitation by social isolation since it has been reported that FS PV interneurons preferentially inhibit $\mathrm{PH}$ cells compared with non-PH cells (Lee et al., 2014). Another possible explanation is that basket interneurons with FS features have somatic inhibition, which might have been preferentially detected since we performed whole-cell patch clamp recording from the soma of pyramidal cells (Freund and Katona, 2007). FS interneurons are primarily detected as PV+ cells. However, SST+ interneurons have been reported to have quasi FS patterns similar to those observed in PV+ interneurons (He et al., 2016). Therefore, we might have included SST interneuron with FS patterns as FS cells given the definition used in this study. Although, we did not detect alterations in the excitability and excitatory synaptic inputs of non-FS cells by social isolation, we cannot exclude the possibility that a subgroup of non-FS interneurons may have contributed to the increased inhibitory synaptic inputs induced by social isolation. Non-FS interneurons that were recorded could include subgroups of GABAergic interneurons that express cholecystokinin, SST, vasointestinal peptide, et cetera. For instance, one possible subgroup may be SST+ interneurons which are important for social exploration (Scheggia et al., 2020).

Previous studies have reported impaired E/I balance in the mPFC of autism-like mouse models with sociability deficits, which was similarly observed in the social isolation animal model (Makinodan et al., 2012). Correcting these imbalances has been reported to normalize key autistic-like phenotypes in these animals (Selimbeyoglu et al., 2017). Yang et al. (2018) revealed that Kv1.2 channel loss in basket cells exaggerated GABA release, which compromises firing activity in the cerebellum. Docosahexaenoic acid, an allosteric Kv1.2 agonist, has been reported to correct this dysregulated inhibition in vitro, as well as the acoustic startle reflex and social interaction in vivo in Fmr1-KO mice. Similarly, pharmacological inhibition of the excitability of FS interneurons might enhance the excitability of $\mathrm{PH}$ cells and improve mPFC function, and thus treat disorders induced by poor environments, such as social isolation.

\section{DATA AVAILABILITY STATEMENT}

All datasets generated for this study are included in the article/Supplementary Material.

\section{ETHICS STATEMENT}

The animal study was reviewed and approved by The animal care and use committee of Nara Medical University.

\section{AUTHOR CONTRIBUTIONS}

HY and KY contributed to the conception and design of the study. KY, YO, HY, KO, and YN performed the experiments. KY analyzed the data. KY and HY wrote the article. MM, YS, and TK supervised the project. All authors contributed to manuscript revision, read, and approved the submitted version.

\section{FUNDING}

This work was supported by the Naito Foundation, the Uehara Memorial Foundation, the Mochida Foundation (Mochida Memorial Foundation for Medical and Pharmaceutical Research), and the Japanese Society for the Promotion of Science.

\section{SUPPLEMENTARY MATERIAL}

The Supplementary Material for this article can be found online at: https://www.frontiersin.org/article/10.3389/fncel.2020.00105/ full\#supplementary-material. 


\section{REFERENCES}

Andersson, R., Johnston, A., and Fisahn, A. (2012). Dopamine D4 receptor activation increases hippocampal $\gamma$ oscillations by enhancing synchronization of fast-spiking interneurons. PLoS One 7:e40906. doi: 10.1371/journal.pone. 0040906

Ascoli, G. A., Alonso-Nanclares, L., Anderson, S. A., Barrionuevo, G., BenavidesPiccione, R., Burkhalter, A., et al. (2008). Petilla terminology: nomenclature of features of GABAergic interneurons of the cerebral cortex. Nat. Rev. Neurol. 9, 557-568. doi: 10.1038/nrn2402

Bick, J., Fox, N., Zeanah, C., and Nelson, C. A. (2017). Early deprivation, atypical brain development, and internalizing symptoms in late childhood. Neuroscience 342, 140-153. doi: 10.1016/j.neuroscience.2015.09.026

Bicks, L. K., Koike, H., Akbarian, S., and Morishita, H. (2015). Prefrontal cortex and social cognition in mouse and man. Front. Psychol. 6:1805. doi: 10.3389/fpsyg.2015.01805

Brumback, A. C., Ellwood, I. T., Kjaerby, C., Iafrati, J., Robinson, S., Lee, A. T., et al. (2018). Identifying specific prefrontal neurons that contribute to autismassociated abnormalities in physiology and social behavior. Mol. Psychiatry 23, 2078-2089. doi: 10.1038/mp.2017.213

Buzsáki, G., Logothetis, N., and Singer, W. (2013). Scaling brain size, keeping timing: evolutionary preservation of brain rhythms. Neuron 80, 751-764. doi: 10.1016/j.neuron.2013.10.002

Cellot, G., and Cherubini, E. (2014). GABAergic signaling as therapeutic target for autism spectrum disorders. Front. Pediatr. 2:70. doi: 10.3389/fped.2014.00070

Chugani, H. T., Behen, M. E., Muzik, O., Juhász, C., Nagy, F., and Chugani, D. C. (2001). Local brain functional activity following early deprivation: a study of postinstitutionalized Romanian orphans. NeuroImage 14, 1290-1301. doi: 10.1006/nimg.2001.0917

Condé, F., Audinat, E., Maire-Lepoivre, E., and Crépel, F. (1990). Afferent connections of the medial frontal cortex of the rat. Brain Res. Bull. 24, 341-354. doi: 10.1016/0361-9230(90)90088-h

Davis, G. W. (2013). Homeostatic signaling and the stabilization of neural function. Neuron 80, 718-728. doi: 10.1016/j.neuron.2013.09.044

Daw, N. W., Reid, S. N., Wang, X. F., and Flavin, H. J. (1995). Factors that are critical for plasticity in the visual cortex. Ciba Found. Symp. 193, 258-276; discussion 322-324. doi: 10.1002/9780470514795.ch13

De Felipe, J., Marco, P., Fairén, A., and Jones, E. G. (1997). Inhibitory synaptogenesis in mouse somatosensory cortex. Cereb. Cortex 7, 619-634. doi: $10.1093 /$ cercor/7.7.619

Dembrow, N. C., Chitwood, R. A., and Johnston, D. (2010). Projectionspecific neuromodulation of medial prefrontal cortex neurons. J. Neurosci. 30, 16922-16937. doi: 10.1523/JNEUROSCI.3644-10.2010

Doischer, D., Hosp, J. A., Yanagawa, Y., Obata, K., Jonas, P., Vida, I., et al. (2008). Postnatal differentiation of basket cells from slow to fast signaling devices. J. Neurosci. 28, 12956-12968. doi: 10.1523/JNEUROSCI.2890-08.2008

Eluvathingal, T. J., Chugani, H. T., Behen, M. E., Juhász, C., Muzik, O., Maqbool, M., et al. (2006). Abnormal brain connectivity in children after early severe socioemotional deprivation: a diffusion tensor imaging study. Pediatrics 117, 2093-2100. doi: 10.1542/peds.2005-1727

Foss-Feig, J. H., Adkinson, B. D., Ji, J. L., Yang, G., Srihari, V. H., McPartland, J. C., et al. (2017). Searching for cross-diagnostic convergence: neural mechanisms governing excitation and inhibition balance in schizophrenia and autism spectrum disorders. Biol. Psychiatry 81, 848-861. doi: 10.1016/j.biopsych.2017. 03.005

Freedman, D. G., King, J. A., and Elliot, O. (1961). Critical period in the social development of dogs. Science 133, 1016-1017. doi: 10.1126/science.133.3457. 1016

Freund, T. F., and Buzsáki, G. (1996). Interneurons of the hippocampus. Hippocampus 6, 347-470. doi: 10.1002/(sici)1098-1063(1996)6:4<347::aidhipo1>3.0.co;2-i

Freund, T. F., and Katona, I. (2007). Perisomatic inhibition. Neuron 56, 33-42. doi: 10.1016/j.neuron.2007.09.012

Galarreta, M., and Hestrin, S. (2002). Electrical and chemical synapses among parvalbumin fast-spiking GABAergic interneurons in adult mouse neocortex. Proc. Natl. Acad. Sci. U S A 99, 12438-12443. doi: 10.1073/pnas.192159599

Gee, S., Ellwood, I., Patel, T., Luongo, F., Deisseroth, K., and Sohal, V. S. (2012). Synaptic activity unmasks dopamine D2 receptor modulation of a specific class of layer V pyramidal neurons in prefrontal cortex. J. Neurosci. 32, 4959-4971. doi: 10.1523/JNEUROSCI.5835-11.2012

Golden, E. C., Graff-Radford, J., Jones, D. T., and Benarroch, E. E. (2016). Mediodorsal nucleus and its multiple cognitive functions. Neurology 87, 2161-2168. doi: 10.1212/WNL.0000000000003344

Gonzalez-Burgos, G., Cho, R. Y., and Lewis, D. A. (2015). Alterations in cortical network oscillations and parvalbumin neurons in schizophrenia. Biol. Psychiatry 77, 1031-1040. doi: 10.1016/j.biopsych.2015.03.010

González-Burgos, G., Krimer, L. S., Povysheva, N. V., Barrionuevo, G., and Lewis, D. A. (2005). Functional properties of fast spiking interneurons and their synaptic connections with pyramidal cells in primate dorsolateral prefrontal cortex. J. Neurophysiol. 93, 942-953. doi: 10.1152/jn.00787.2004

He, M., Tucciarone, J., Lee, S., Nigro, M. J., Kim, Y., Levine, J. M., et al. (2016). Strategies and tools for combinatorial targeting of GABAergic neurons in mouse cerebral cortex. Neuron 91, 1228-1243. doi: 10.1016/j.neuron.2016. 08.021

Holtmaat, A., and Svoboda, K. (2009). Experience-dependent structural synaptic plasticity in the mammalian brain. Nat. Rev. Neurosci. 10, 647-658. doi: $10.1038 / \mathrm{nrn} 2699$

Hughes, D. I., Boyle, K. A., Kinnon, C. M., Bilsland, C., Quayle, J. A., Callister, R. J., et al. (2013). HCN4 subunit expression in fast-spiking interneurons of the rat spinal cord and hippocampus. Neuroscience 237, 7-18. doi: 10.1016/j. neuroscience.2013.01.028

Kalmbach, B. E., Johnston, D., and Brager, D. H. (2015). Cell-type specific channelopathies in the prefrontal cortex of the fmr1-/y mouse model of fragile $\mathrm{X}$ syndrome. eNeuro 2:ENEURO.0114-15.2015. doi: 10.1523/eneuro.011415.2015

Kannan, M., Gross, G. G., Arnold, D. B., and Higley, M. J. (2016). Visual deprivation during the critical period enhances layer 2/3 GABAergic inhibition in mouse V1. J. Neurosci. 36, 5914-5919. doi: 10.1523/JNEUROSCI.005116.2016

Kawaguchi, Y., and Kondo, S. (2002). Parvalbumin, somatostatin and cholecystokinin as chemical markers for specific GABAergic interneuron types in the rat frontal cortex. J. Neurocytol. 31, 277-287. doi: 10.1023/a:1024126110356

Kawaguchi, Y., and Kubota, Y. (1997). GABAergic cell subtypes and their synaptic connections in rat frontal cortex. Cereb. Cortex 7, 476-486. doi: $10.1093 /$ cercor/7.6.476

Kullmann, D. M. (1994). Amplitude fluctuations of dual-component EPSCs in hippocampal pyramidal cells: implications for long-term potentiation. Neuron 12, 1111-1120. doi: 10.1016/0896-6273(94)90318-2

Le Magueresse, C., and Monyer, H. (2013). GABAergic interneurons shape the functional maturation of the cortex. Neuron 77, 388-405. doi: 10.1016/j.neuron 2013.01.011

LeBlanc, J. J., and Fagiolini, M. (2011). Autism: a "critical period" disorder? Neural Plast. 2011:921680. doi: 10.1155/2011/921680

Lee, A. T., Gee, S. M., Vogt, D., Patel, T., Rubenstein, J. L., and Sohal, V. S. (2014). Pyramidal neurons in prefrontal cortex receive subtype-specific forms of excitation and inhibition. Neuron 81, 61-68. doi: 10.1016/j.neuron.2013. 10.031

Lewis, D. A., Fish, K. N., Arion, D., and Gonzalez-Burgos, G. (2011). Perisomatic inhibition and cortical circuit dysfunction in schizophrenia. Curr. Opin. Neurobiol. 21, 866-872. doi: 10.1016/j.conb.2011.05.013

Maffei, A., Nataraj, K., Nelson, S. B., and Turrigiano, G. G. (2006). Potentiation of cortical inhibition by visual deprivation. Nature 443, 81-84. doi: $10.1038 /$ nature 05079

Makinodan, M., Rosen, K. M., Ito, S., and Corfas, G. (2012). A critical period for social experience-dependent oligodendrocyte maturation and myelination. Science 337, 1357-1360. doi: 10.1126/science.1220845

Markram, H., Toledo-Rodriguez, M., Wang, Y., Gupta, A., Silberberg, G., and $\mathrm{Wu}, \mathrm{C}$. (2004). Interneurons of the neocortical inhibitory system. Nat. Rev. Neurosci. 5, 793-807. doi: 10.1038/nrn1519

Micheva, K. D., and Beaulieu, C. (1996). Quantitative aspects of synaptogenesis in the rat barrel field cortex with special reference to GABA circuitry. J. Comp. Neurol. 373, 340-354. doi: 10.1002/(sici)1096-9861(19960923)373:3<340::aidcne3>3.0.co; $2-2$

Nahmani, M., and Turrigiano, G. G. (2014). Deprivation-induced strengthening of presynaptic and postsynaptic inhibitory transmission in layer 4 of 
visual cortex during the critical period. J. Neurosci. 34, 2571-2582. doi: 10.1523/JNEUROSCI.4600-13.2014

Nair, A., Treiber, J. M., Shukla, D. K., Shih, P., and Müller, R. A. (2013). Impaired thalamocortical connectivity in autism spectrum disorder: a study of functional and anatomical connectivity. Brain 136, 1942-1955. doi: 10.1093/brain/awt079

Neher, E. (1992). Correction for liquid junction potentials in patch clamp experiments. Methods Enzymol. 207, 123-131. doi: 10.1016/00766879(92)07008-c

Nelson, S. B., and Valakh, V. (2015). Excitatory/inhibitory balance and circuit homeostasis in autism spectrum disorders. Neuron 87, 684-698. doi: 10.1016/j. neuron.2015.07.033

Parnaudeau, S., Taylor, K., Bolkan, S. S., Ward, R. D., Balsam, P. D., and Kellendonk, C. (2015). Mediodorsal thalamus hypofunction impairs flexible goal-directed behavior. Biol. Psychiatry 77, 445-453. doi: 10.1016/j.biopsych. 2014.03.020

Pawelzik, H., Hughes, D. I., and Thomson, A. M. (2002). Physiological and morphological diversity of immunocytochemically defined parvalbumin- and cholecystokinin-positive interneurones in CA1 of the adult rat hippocampus. J. Comp. Neurol. 443, 346-367. doi: 10.1002/cne.10118

Petrini, E. M., Ravasenga, T., Hausrat, T. J., Iurilli, G., Olcese, U., Racine, V., et al. (2014). Synaptic recruitment of gephyrin regulates surface $\mathrm{GABA}_{A}$ receptor dynamics for the expression of inhibitory LTP. Nat. Commun. 5:3921. doi: $10.1038 /$ ncomms 4921

Qiu, S., Anderson, C. T., Levitt, P., and Shepherd, G. M. (2011). Circuitspecific intracortical hyperconnectivity in mice with deletion of the autismassociated Met receptor tyrosine kinase. J. Neurosci. 31, 5855-5864. doi: 10.1523/JNEUROSCI.6569-10.2011

Ray, J. P., and Price, J. L. (1992). The organization of the thalamocortical connections of the mediodorsal thalamic nucleus in the rat, related to the ventral forebrain-prefrontal cortex topography. J. Comp. Neurol. 323, 167-197. doi: $10.1002 / \mathrm{cne} .903230204$

Ray, J. P., and Price, J. L. (1993). The organization of projections from the mediodorsal nucleus of the thalamus to orbital and medial prefrontal cortex in macaque monkeys. J. Comp. Neurol. 337, 1-31. doi: 10.1002/cne.903370102

Rinaldi, T., Perrodin, C., and Markram, H. (2008a). Hyper-connectivity and hyper-plasticity in the medial prefrontal cortex in the valproic acid animal model of autism. Front. Neural Circuits 2:4. doi: 10.3389/neuro.04.004.2008

Rinaldi, T., Silberberg, G., and Markram, H. (2008b). Hyperconnectivity of local neocortical microcircuitry induced by prenatal exposure to valproic acid. Cereb. Cortex 18, 763-770. doi: 10.1093/cercor/bhm117

Rotaru, D. C., Yoshino, H., Lewis, D. A., Ermentrout, G. B., and GonzalezBurgos, G. (2011). Glutamate receptor subtypes mediating synaptic activation of prefrontal cortex neurons: relevance for schizophrenia. J. Neurosci. 31, 142-156. doi: 10.1523/JNEUROSCI.1970-10.2011

Scheggia, D., Manago, F., Maltese, F., Bruni, S., Nigro, M., Dautan, D., et al. (2020). Somatostatin interneurons in the prefrontal cortex control affective state discrimination in mice. Nat. Neurosci. 23, 47-60. doi: 10.1038/s41593019-0551-8
Selimbeyoglu, A., Kim, C. K., Inoue, M., Lee, S. Y., Hong, A. S. O., Kauvar, I., et al. (2017). Modulation of prefrontal cortex excitation/inhibition balance rescues social behavior in CNTNAP2-deficient mice. Sci. Transl. Med. 9:eah6733. doi: 10.1126/scitranslmed.aah6733

Takesian, A. E., and Hensch, T. K. (2013). Balancing plasticity/stability across brain development. Prog. Brain Res. 207, 3-34. doi: 10.1016/b978-0-444-633279.00001-1

Tamura, R., Kitamura, H., Endo, T., Hasegawa, N., and Someya, T. (2010). Reduced thalamic volume observed across different subgroups of autism spectrum disorders. Psychiatry Res. 184, 186-188. doi: 10.1016/j.pscychresns. 2010.07.001

Tan, G. C., Doke, T. F., Ashburner, J., Wood, N. W., and Frackowiak, R. S. (2010). Normal variation in fronto-occipital circuitry and cerebellar structure with an autism-associated polymorphism of CNTNAP2. NeuroImage 53, 1030-1042. doi: 10.1016/j.neuroimage.2010.02.018

Tricoire, L., Pelkey, K. A., Erkkila, B. E., Jeffries, B. W., Yuan, X., and McBain, C. J. (2011). A blueprint for the spatiotemporal origins of mouse hippocampal interneuron diversity. J. Neurosci. 31, 10948-10970. doi: 10.1523/JNEUROSCI. 0323-11.2011

Weaver, I. C., Cervoni, N., Champagne, F. A., D’Alessio, A. C., Sharma, S., Seckl, J. R., et al. (2004). Epigenetic programming by maternal behavior. Nat. Neurosci. 7, 847-854. doi: 10.1038/nn1276

Yamamuro, K., Yoshino, H., Ogawa, Y., Makinodan, M., Toritsuka, M., Yamashita, M., et al. (2018). Social isolation during the critical period reduces synaptic and intrinsic excitability of a subtype of pyramidal cell in mouse prefrontal cortex. Cereb. Cortex 28, 998-1010. doi: 10.1093/cercor/bhx010

Yang, Y. M., Arsenault, J., Bah, A., Krzeminski, M., Fekete, A., Chao, O. Y., et al. (2018). Identification of a molecular locus for normalizing dysregulated GABA release from interneurons in the Fragile X brain. Mol. Psychiatry doi: 10.1038/s41380-018-0240-0 [Epub ahead of print].

Yizhar, O., Fenno, L. E., Prigge, M., Schneider, F., Davidson, T. J., O'Shea, D. J., et al. (2011). Neocortical excitation/inhibition balance in information processing and social dysfunction. Nature 477, 171-178. doi: 10.1038/nature10360

Zucker, R. S., and Regehr, W. G. (2002). Short-term synaptic plasticity. Annu. Rev. Physiol. 64, 355-405. doi: 10.1146/annurev.physiol.64.092501.114547

Conflict of Interest: The authors declare that the research was conducted in the absence of any commercial or financial relationships that could be construed as a potential conflict of interest.

Copyright (๑) 2020 Yamamuro, Yoshino, Ogawa, Okamura, Nishihata, Makinodan, Saito and Kishimoto. This is an open-access article distributed under the terms of the Creative Commons Attribution License (CC BY). The use, distribution or reproduction in other forums is permitted, provided the original author(s) and the copyright owner(s) are credited and that the original publication in this journal is cited, in accordance with accepted academic practice. No use, distribution or reproduction is permitted which does not comply with these terms. 